\title{
Effect of pH on the ability of N-terminal domain of human NPC1 to recognize, bind, and transfer cholesterol.
}

\author{
Shelby M. Baker ${ }^{1}$, Marharyta Petukh ${ }^{1 a}$ \\ ${ }^{1}$ Presbyterian College, Clinton, SC
}

Key words: Niemann-Pick type C1; N-terminal domain; cholesterol; $\mathrm{pH}$.

\footnotetext{
${ }^{a}$ To whom correspondence should be addressed. Email: mpetukh@ presby.edu
} 
The energy output from the production stage of MD simulations were used to roughly estimate how the binding energy of CLR changes due to $\mathrm{pH}$ variation from 4.5 to 7.2.

The change in binding energy was calculated with:

$$
\Delta \Delta G^{4.5 \rightarrow 7.2}(\text { binding })=G^{7.2}(\text { holo })-G^{7.2}(\text { apo })-G^{4.5}(\text { holo })+G^{4.5}(\text { apo }),
$$

where $G$ is free energy of NPC1(NTD) in apo state or with bound CLR at specific pH. Here we assumed that the free energy of CLR does not depend on $\mathrm{pH}$. For the simplicity, we used potential energy of the protein in apo- and holo- states.

Table S1. The change in binding energy of CLR due to $\mathrm{pH}$ variation.

$$
\begin{array}{crc} 
& <G(\text { apo })>, \text { kcal } / \mathrm{mol} & \langle G(\text { holo })>\text {, } k \text { cal } / \mathrm{mol} \\
\mathrm{pH}=4.5 & -1827.57 & -1821.17 \\
\mathrm{pH}=7.2 & -2259.94 & -2245.33 \\
& & \\
& &
\end{array}
$$

